\title{
ACESSO À JUSTIÇA À LUZ DA OBRA VIDAS SECAS DE GRACILIANO RAMOS
}

\author{
Leticia Rodrigues Biassoti, Fábio Morong, Flávia Marsola \\ Universidade do Oeste Paulista - UNOESTE, curso de Direito, Presidente Prudente, SP. E-mail: \\ leticiabiassoti@outlook.com; fla marsola@hotmail.com; fabiomorong@hotmail.com
}

\begin{abstract}
RESUMO
O objetivo desse trabalho é analisar duas áreas consideradas distantes, quais sejam, o Direito e a Literatura à luz da obra Vidas Secas de Graciliano Ramos correlacionado ao tema Acesso à Justiça. Demonstrar que podem se interagir e apontar reflexões sobre a sociedade e impactos gerados no próprio indivíduo, principalmente àqueles que não possuem de fato o conhecimento de que são cidadãos de direito, por não terem alcance aos pilares básicos para uma vida digna por meio do acesso à justiça. Aplicou-se o método dedutivo para sistematizar os dados coletados e consultas à legislação nacional, doutrinas relevantes na matéria objeto de estudo e obras literárias. Entender através dos apontamentos e comparações que não existe uma verdade e regra absoluta para tudo, e que o Direito por mais perfeito que possa estar nas escritas, necessita estar da mesma forma na prática, muitas vezes sendo quase impossível, e qual a razão de obter uma nova visão sobre realidades díspares.
\end{abstract}

Palavras-chave: Direito. Literatura. Acesso à justiça. Sociedade. Conhecimento.

\section{ACCESS TO JUSTICE: IN THE LIGHT OF THE WORK DRY LIVES OF GRACILIANO RAMOS}

\section{ABSTRACT}

The objective of this work is to analyze two areas considered to be distant, Law and in the light of the work Vidas Secas de Graciliano Ramos correlated to the theme Access to Justice Demonstrate that they can interact and point out reflections about society and the impacts generated in the individual, especially those who do not really have the knowledge that they are citizens with rights, because they do not have access to the basic pillars for a dignified life through access to the justice. The deductive method was applied to systematize the collected data and consultations to the national legislation, relevant doctrines in the matter object of study and literary works. To understand through notes and comparisons that there is no truth and absolute rule for all, and that the most perfect Law that may be in the writings, needs to be in the same way in practice, often being almost impossible, and what is the reason for obtaining a new vision about different realities.

Keywords: Law. Literature. Access to justice. Society. Knowledge

\section{INTRODUÇÃO}

O Direito é uma ciência social que possui diversas definições e pode ser apontado como diretrizes coercitivas que auxiliam e moldam o comportamento humano para alcançar a ordem e a paz social. De igual forma, um conjunto de valores éticos e morais que permitem ao indivíduo defender seus interesses, sendo uma faculdade e um dever. Todavia, há algo em comum, o estudo. Busca-se o conhecimento do ser humano, dotado de sentimentos, sendo interligados pela vida em sociedade, que requer necessariamente imposição de limites.

A realização dessas combinações ocorreu através da linguagem, permitida pela comunicação, que passou por processos de evolução até chegar ao que temos atualmente, o 
diferencial do homem com os outros seres. A partir disso, além de outras áreas, o homem passou a dominar também a linguagem, de modo que surgiu a Literatura - arte das palavras - que possibilita transformar a realidade vivida em uma ficção única, um ambiente em que a criação de algo além dos moldes em que vivemos é praticável.

Essas duas áreas se complementam, obras literárias trazem visões mais amplas do que as geralmente apresentadas aos acadêmicos de Direito, em que o foco habitual é um aprendizado pragmático, a escrita mais informal que provoca proximidade do leitor, e o mais importante, é a percepção de que tudo que está narrado tem uma verdade nas entrelinhas, seja com uso de metáforas, dialetos, rimas, bastando a conjugação dos saberes para notar que o Direito, o senso de justo, diferenças sociais, está em tudo e em todos, inclusive nos mais humildes.

O enfoque deste trabalho está voltado à obra de Graciliano Ramos "Vidas secas", com o objetivo de apresentar pareceres da área jurídica considerando o Acesso à Justiça. $O$ que ela engloba, as barreiras, as consequências desses impedimentos na vida de um indivíduo já em situação de desigualdade e precariedade, questionar o funcionamento de fato, até onde é aplicado na sociedade brasileira, levando em consideração as diferentes realidades encontradas no país, devido os fatores educacionais, financeiros, psicológicos, em especial, na realidade nordestina.

\section{DESENVOLVIMENTO}

\section{CONTEXTO LITERÁRIO}

Em 1938 foi publicada a referida obra de Graciliano Ramos, nesse período (1930 -1945), devido a ocorrência das guerras, ditaduras, instabilidades políticas e econômicas, uma atenção maior foi empregada ao tema homem versus sociedade. O autor assim desenvolveu um livro voltado para o regionalismo com ênfase no Nordeste. Com os problemas sociais encontrados, a seca, a miséria e acima de tudo, a indiferença com a população. (SILVA, 2017).

As consequências foram inúmeras, os direitos foram esquecidos por um momento, 0 Estado passou a não cumprir seu papel de protetor social, o que influenciou em um dos pilares básicos para ter a vida digna, a cidadania. Esta, cada vez mais comprometida, trazia insegurança, e um grande abismo foi criado entre os indivíduos.

De acordo com Batista (2010, p. 96), observa-se que:

(...) No Brasil, a exclusão social é um processo decorrente de crise econômica que inclui uma separação entre o pobre e o rico, sendo excluído da sociedade aquele que não tem condições financeiras de ter uma boa educação, de habitar em um bairro mediano ou nobre, de ter ingresso no emprego, de ter acesso à Justiça, ou seja, é àquele que não exerce devidamente sua cidadania.

A exclusão social ganhou amplitude por meio de grandes e duradouras crises no país, criou raízes complexas a serem eliminadas, um desafio para os representantes do país solucionarem.

\section{REALIDADE NA SECA E CONSEQUÊNCIAS}

O romance "Vidas Secas" (RAMOS 2016), traz a história de uma família de retirantes, Fabiano, Sinhá Vitória, O Menino Mais Novo, O Menino Mais Velho, e por fim, a cachorra Baleia, que vivem à mercê das estações, das condições climáticas e das impostas por tirarem sua subsistência de patrões rudes, uma vida pacata, miserável, com pouca esperança. Todos possuem 
participação exclusiva nas divisões dos capítulos, entretanto, Fabiano é o protagonista, o principal narrador e nele está o ponto central dos questionamentos.

Um indivíduo desafortunado raramente vê a sua volta possibilidades de progresso, e segundo Ramos (2016, p. 97), Fabiano acreditava ter nascido com um destino ruim, designado a trabalhar para os outros - serviços braçais de pouca valorização e rentabilidade - bem como seus familiares haviam feito, estava no sangue, e nada poderia mudar essa situação.

Claramente, o personagem, por falta de conhecimento não percebe que está enquadrado na teoria do determinismo, e a partir dessa consciência de imutabilidade, ocorre uma série de eventos que tornam o homem prisioneiro de si mesmo, como a submissão ao próximo, a ausência de luta por seus direitos e o entendimento que os mesmos existem. Sobre o tema, Dallari (1991, p. 18) descreve:

Qual o fundamento em que se apóiam [sic] os deterministas? Dizem eles que o homem está submetido, inexoravelmente, a uma série de leis naturais, sujeitos ao princípio da causalidade. Por essa razão, embora exista a possibilidade de interferir em pormenores da vida social, há um fator ou há vários fatores determinando a sucessão dos fatos fundamentais. Para alguns deterministas esse fator é de ordem econômica, para outros é de ordem geográfica, havendo ainda várias outras correntes deterministas, todas tendo em comum a afirmativa de que o homem tem sua vida social condicionada por certo fator, não havendo a possibilidade de se escolher um objetivo e de orientar para ele a vida social.

Os cidadãos que se encontram enquadrados nesses fatores determinantes se assemelham ao mecanismo de uma roda-gigante: em um momento há o ápice, onde a visão se torna privilegiada (possibilidade de mudança de vida), em outro há o declínio, onde a visão regressa ao inicial, o chão (realidade encontrada - decepção) e por fim, há somente um único caminho a ser seguido, as incansáveis voltas da roda, e as incansáveis permanências do destino.

\section{O DIREITO VISTO POR QUEM NÃO O VÊ}

Como um indivíduo completamente desafortunado e com pouco aprendizado pode ainda ter noção que o Governo existe? Saber que algo é injusto ou justo? Um dos momentos mais marcantes da obra ocorre quando Fabiano entra em um jogo já embriagado e dentre os participantes está um policial que recebe a denominação de "Soldado amarelo", e com o decorrer do tempo, Fabiano se exalta durante a partida e disfere um xingamento relacionado a mãe da autoridade, que faz com que ele sofra agressão e seja mandado para a cadeia, condenado a passar a noite.

Assim está descrito na obra "Fabiano marchou desorientado, entrou na cadeia, ouviu sem compreender uma acusação medonha e não se defendeu". (RAMOS, 2016, p. 31). Com a decorrência desse fato, ele deixa de ser homem e passa a ser bicho, uma vez que foi negado um dos mais importantes e norteadores princípios do Direito, o do devido processo legal. "Ninguém será privado de liberdade ou de seus bens sem o devido processo legal." (CONSTITUIÇÃO DA REPÚBLICA FEDERATIVA DO BRASIL, art 5으, inc. LIV).

Neste caso, o acesso à justiça o abrange, haja vista que, para que esse seja efetivo, existem condições a serem respeitadas, primeiro, todo ser deve ter consciência de que pode e deve utilizar de instrumentos e meios para defender seus interesses e anseios, mas antes, necessita ter conhecimento destes. 
Neste sentido "A força de um povo corresponde à do seu sentimento do direito; é, pois, velar pela segurança e força do Estado o cultivar o sentimento legal da Nação não só no que se refere à escola e ensino, como também no que toca à aplicação prática da justiça em todas as situações e momentos da vida." (IHERING, 2014, p. 85)

Em um segundo momento, por meio do intelecto, um indivíduo deve discernir se seus atos praticados são passiveis de defesa, em terceiro, procurar os responsáveis por lei para que seja corretamente atendido, considerando aqui sua condição financeira para que utilize por exemplo, das serventias do Estado, como a defensoria pública. E por fim, resta claro que o que está escrito na Carta Magna deve ser respeitado, principalmente ao que diz respeito aos direitos e garantias fundamentais (rol do art. 5o), incluído aqui, o devido processo legal que é a garantia de que todas as etapas de um processo serão respeitadas de acordo com as leis e os critérios processuais sob pena de nulidade, neste caso especifico, houve violação do direito da mais ampla defesa.

Segundo Cappelletti e Garth (1988, p. 5), "O acesso à justiça pode, portanto, ser encarado como o requisito fundamental - o mais básico dos direitos humanos - de um sistema jurídico moderno $e$ igualitário que pretenda garantir, e não apenar proclamar os direitos de todos".

No entanto, Fabiano, tinha conhecimento disso, porém não entendia a razão. " $E$, por mais que forcejasse, não se convencia de que o soldado amarelo fosse governo. Governo, coisa distante e perfeita, não podia errar". (RAMOS, 2016, p. 33). O real motivo consta nos ensinamentos em uma das frases proferidas por mais um gênio da Literatura brasileira, Monteiro Lobato, que expressa "Quem mal lê, mal ouve, mal fala, mal vê."

Ramos expõe (2016, p. 35):

(...). Vivia tão agarrado aos bichos.... Nunca vira uma escola. Por isso não conseguia defender-se, botar as coisas nos seus lugares. O demônio daquela história entrava-lhe na cabeça a saía. Era para um cristão endoidecer. Se Ihe tivessem dado ensino, encontraria meio de entende-la. Impossível, só sabia lidar com bichos. (...). Era bruto, sim senhor, nunca havia aprendido, não sabia explicar-se. Estava preso por isso? Como era? Então mete-se um homem na cadeia porque ele não sabe falar direito? Que mal fazia a brutalidade dele? Vivia trabalhando como um escravo.

Percebe-se que este é o reflexo de uma pessoa que não possui preparo suficiente para saber lidar com o grupo social o qual pertence, é a demonstração de alguém que não tem contato qualquer com a justiça, não desfruta de formação educacional que o permita contestar, e não se submeter a situações constrangedoras. Seu interior é contido, de modo que as relações humanas se transformam em algo inacessível, o que foge do cotidiano, se torna hostil, como está explanado em um dos trechos da obra de Ramos $(2016$, p. 20) as palavras "da gente da cidade" que apesar de admiradas e compridas, eram inúteis e perigosas.

De acordo com Batista (2010, p. 72), quase todo o território brasileiro é formado por pessoas que não tiveram a oportunidade de frequentar uma escola, e que fator principal é a pobreza, realidade de quase um terço da nação brasileira, o que reflete diretamente na aptidão de reconhecer a titularidade de um direito e que este possa ser protegido, uma vez que os carentes de educação e recursos financeiros são os mais atingidos.

O direito visto por quem não o vê, é como a legislação se mostra aos olhos de quem dispõe de conhecimento mínimo, [...] Se viver sem amor é difícil, sem justiça é impossível. Ela não deve ser negada nem a pobres nem a ricos, nem a fracos nem a poderosos. (ARAÚJO, 1995, p. 305).

A justiça deve ser alcançada por todos, independentemente do estilo de vida, status social e acima de tudo, grau de intelecto. 


\section{ORDENAMENTO JURÍDICO - CONSIDERAÇÕES GERAIS}

Para que haja apreciação de múltiplas opiniões e pareceres faz-se necessária a existência de previsão legal que forneça fundamentação. $O$ nosso ordenamento se exibe repleto de artigos sobre o tema, em sua maioria constados na Constituição Federal, que asseguram direitos como: apreciação para todos sobre lesão ou ameaça a direito (art. 5o, XXXV), prestação de assistência jurídica aos com recursos insuficientes (art. 5o, LXXIV), bem como a defensoria pública como instituição permanente, essencial à função jurisdicional do Estado (art. 134).

Consoante a opinião de Moraes (2016, p. 36), a Constituição de 1988 adotou o princípio da igualdade de direitos, ou seja, todos os cidadãos devem ser tratados de maneira igual pela lei, de maneira que se proíba discriminações e distinções. Seguindo o raciocínio, Nader (2015), considera que, o respeito aos direitos fundamentais deve ser absoluto, além de constados na Constituição devem estar protegidos por meios que os efetivem nos casos concretos, ou seja, com um judiciário bem estruturado e efetiva prestação jurisdicional.

Dessa maneira, a nossa legislação não aparenta carecer de uma mudança primordial, e sim, de contemplação quanto a aplicabilidade e a vida dos cidadãos.

\section{CONCLUSÃO}

Se verifica que, não é o bastante ter direitos salvaguardados com formalidade e rigidez sem antes identificar onde está a problemática. A Constituição Federal engloba tudo o que é necessário para a composição de uma sociedade justa e igualitária, as disciplinas processuais apontam como cada etapa deve ser efetuada e cumprida para assegurar a efetividade do direito material, todavia, o Acesso à justiça, possui fraturas que necessitam de reparos.

As análises desse tema, foram realizadas sob um prisma genérico, com intuito de buscar meios e instrumentos viabilizadores para alcançar o acesso, formas de diminuir custos, serviços instaurados em locais periféricos ou afastados na tentativa de aproximar a população. $O$ que se esquece é a existência do princípio da especialidade, pois a norma especial prevalece sobre a norma geral, aplicado aqui, significa que seja país, região, ou qualquer determinação geográfica, encontraremos variações importantíssimas, que constatarão as barreiras a serem derrubadas de acordo com a realidade encontrada.

No Brasil, como na obra, especialmente o Nordeste, a escassez é encontrada na forma como se vive, em todos os aspectos possíveis, existem inúmeras famílias como a de Fabiano ainda hoje, que vivem na miséria, sendo ela alimentar, de bem-estar, de educação, respeito e dignidade. O Acesso à justiça neste caso, não se tornaria legítimo e eficaz se generalizado, eis que a adversidade é ampla, é governamental, é estatal, e política. Intervenções são necessárias, e exceções também, a medida que os elementos que compõe o corpo social não são bem distribuídos.

O impasse do Acesso à Justiça não se reflete aos profissionais da área, nem ao menos os métodos propostos, é acreditar que apenas isso acabará com as diferenças. Assim, indispensável seria que o a nossa gestão política focasse onde mais requer atenção, ou seja, criação de escolas, centros de atendimento, facilidades para integrar a vida em sociedade, seja por meio de emprego, transporte público, recursos estes que aproximem todos do Poder Judiciário, de forma que o tratamento social seja baseado na equidade, ao invés da igualdade.

\section{REFERÊNCIAS BIBLIOGRÁFICAS}

ARAÚJO, Francisco Fernandes de. A cara da justiça. 1. ed. São Paulo: Capola livros LTDA, 1995. 
BATISTA, Keila Rodrigues. Acesso à justiça: instrumentos viabilizadores. 1. ed. São Paulo: Letras Jurídicas, 2010.

BRASIL. Constituição. (1988). Constituição da República Federativa do Brasil. Brasília: Senado Federal, 2016.

CAPPELLETTI, M.; GARTH, B.; Acesso à Justiça. Reimpresso/2002. Porto Alegre: Sergio Antonio Fabris Editor, 1988.

DALLARI, Dalmo de Abreu. Elementos da teoria geral do Estado. 16. ed. São Paulo: Editora Saraiva, 1991

IHERING, Rudolf Von. A luta pelo direito. 1. ed. São Paulo: CL EDIJUR - Editora e Distribuidora Jurídica, 2014.

MORAES, Alexandre de. Direito Constitucional. 32. ed. São Paulo: Editora GEN, 2016.

NADER, Paulo. Filosofia do Direito. 23. Ed. Rio de Janeiro: Editora Forense LTDA, 2015. Disponível em: https://integrada.minhabiblioteca.com.br/\#/books/978-85-309-6475-7/ Acesso em: 31 de julho de 2017.

RAMOS, Graciliano. Vidas Secas. 131. ed. Rio de Janeiro: Editora Record LTDA, 2016.

SILVA, Marina Cabral da. "O Modernismo no Brasil - 2a fase"; Brasil Escola. Disponível em: <http://brasilescola.uol.com.br/literatura/o-modernismo-no-brasil2-fase.htm>. Acesso em 02 de agosto de 2017. 